\title{
Comparison of Established Risk Factors among Type 2 Diabetic Patients with or without Retinopathy in Golestan Hospital, Ahvaz 2010
}

\author{
Homeira Rashidi*, Ali Kasiri, Seyed Mahmoud Latifi, Ferdos Zaman, Hajieh Shahbazian, \\ Armaghan Moravej Aleali \\ Health Research Institute, Diabetes Research Center, Ahvaz Jundishapur University of Medical Sciences, Ahvaz, \\ Iran \\ Email: ${ }^{\text {hrashidi2002@gmail.com }}$
}

Received 8 September 2014; revised 30 September 2014; accepted 10 October 2014

Copyright (C) 2014 by authors and Scientific Research Publishing Inc.

This work is licensed under the Creative Commons Attribution International License (CC BY). http://creativecommons.org/licenses/by/4.0/

(c) (i) Open Access

\begin{abstract}
The aim of this study was to establish diabetic retinopathy correlation with several risk factors. A prospective study including 256 type II diabetic patients who referred to diabetes's clinic was designed. All patients underwent physical \& retina examination and then completed questionnaire including duration of DM, cardiovascular disease, stroke, chronic kidney disease, smoking, and kind of treatment, blood pressure, BMI, abdominal \& hip circumference. Results of HbA1C, total cholesterol, HDL \& LDL cholesterol, TG, FBS, creatinine, 24-h urine microalbumin were recorded. Data were analyzed by SPSS version 17 with $K^{2}$, independent samples $T$, and logistic regression. Of 256 types II diabetic patients $81 \& 175$ were men and women respectively. Mean age of subject was $54 \pm 10.27$. Prevalence of diabetic retinopathy was $22.3 \%$ \& macula edema $0.5 \%$ \& PDR $6 \%$ \& NPDR 14\%; diabetic retinopathy was associated with duration of $D M \& B M I(P=0, P=0.43$ respectively). Mean of FBS $191 \pm 83$ vs. $165.7 \pm 74.5(\mathrm{P}=0.03)$, HbA1c $9.1 \pm 2$ vs. $8.5 \pm 1.9(\mathrm{P}=0.02)$, 24-h urine microalbumin $181.2 \pm 404.7$ vs. $60.2 \pm 236(P=0.03)$, Systolic blood pressure $124.3 \pm$ 21.3 vs. $118.5 \pm 17.8(p=0.04)$ differed between diabetic patients with or without diabetic retinopathy. There were no significant difference between subject with $\&$ without diabetic retinopathy in total cholesterol LDL, HDL, TG, Cr, Diastolic BP, types of treatment, cardiovascular disease, chronic kidney disease, stroke $\&$ smoking. This study showed prevalence of diabetic retinopathy was high and it associated with duration of DM, BMI, FBS, HbA1C, 24-h urine albumin, and systolic blood pressure.
\end{abstract}

${ }^{*}$ Corresponding author.

How to cite this paper: Rashidi, H., et al. (2014) Comparison of Established Risk Factors among Type 2 Diabetic Patients with or without Retinopathy in Golestan Hospital, Ahvaz 2010. Open Journal of Endocrine and Metabolic Diseases, 4, 225229. http://dx.doi.org/10.4236/ojemd.2014.410022 


\section{Keywords}

\section{Diabetic Retinopathy, Type II DM, Retinopathy Risk Factors}

\section{Introduction}

The prevalence of diabetes is increasing worldwide [1]. Despite advances in the treatment of diabetes during the last two decades, many people with diabetes are at high risk for microvascular complications of the disease such as diabetic neuropathy and diabetic retinopathy [2]. Diabetic retinopathy is the most common complication of type 2 diabetes, [3] and one of the most important causes for disorder of visual loss in patients aged 74 - 25 years throughout the world. With increasing duration of diabetes, the prevalence of DR will be greater than before.

In addition, controlling blood sugar levels, presence or absence of hypertension, smoking, neuropathy, dyslipidemia and pregnancy are other effective risk factors [4].

The presence of diabetic retinopathy is an indicator for increasing morbidity and mortality (including cardiovascular complications [5]-[6]). Patients with proliferative retinopathy and non-proliferative retinopathy compared with patients without retinopathy are facing with a high risk of cardiovascular events, including MI, Stroke, Revascularization, and death from CVD [7].

Screening for diabetic retinopathy is important, because the large number of patients had no symptoms with progression of retinopathy to the macular edema (ME) and or proliferative diabetic retinopathy (PDR). On the other hand, the effect of laser photocoagulation in preventing vision loss from proliferative retinopathy and macular edema has been marked in the randomized trials. Early prevention of retinopathy is more important than the treatment of established retinopathy. In this study we determine the prevalence of retinopathy. In the study, we determined the prevalence of retinopathy and its risk factors among patients with diabetes mellitus that referred to diabetes clinic in Golestan Hospital.

\section{Materials and Methods}

In this descriptive analytical study 256 patients were evaluated. The study protocol adhered to the tenets of the Declaration of Helsinki. Informed consent was provided by all the participants. This research project has been approved by ethical committee of University of Medical sciences.

In this study, 256 patients referred to the diabetic clinic in hospital of during the 2009, which diagnosis of diabetes in them was done based on criteria ADA 2003, were examined. At the initial visit, the data sheet were completed about the duration of their disease, previous history of cardiovascular disease, stroke, chronic kidney disease, smoking history, family history of diabetes and diabetic retinopathy, and the type of treatment used during illness, and the data was recorded.

Then, the patients' blood pressure, BMI, and abdominal, hip circumference ratio were measured. Level glycosylated hemoglobin was measured using reader II NYCO card II by UV method. Also, serum cholesterol, triglycerides, creatinine and fasting blood glucose levels were measured by enzymatic colorimetric test; and serum level of HDL was measured by direct methods, antibody enzyme method; Low-Density Lipoprotein (LDL) was calculated Fridwald's Formula; and 24-hour urine microalbumin was measured by immunoturbidometric method; 24-hour urine microalbumin using kits of Pars Azmoon Co. was done by autoanalyzer BT 3000. Diabetes duration was considered the period from diagnosis of diabetes mellitus by study onset.

Patients were evaluated by an ophthalmologist who had no information about metabolic control of the patients. Retinal examination was performed by an ophthalmologist using direct and indirect through dilated pupils with ophthalmoscope of TOPCON and by Slit-Lamp TOPCON, along with 90 +VOLKE lens. Data were analyzed using SPSS v.17.

\section{Results}

In the study, 256 patients with diabetes attending the diabetes clinic of Golestan hospital of Ahvaz in 2010 were studied of which 81 were male (31.7\%) and 175 females (68.3\%).

Patients aged 15 - 87 years in the study with an average of $54 \pm 10.27$. Duration of diagnosed diabetes was 1 - 
384 months with an average $93.39 \pm 78.6$. Prevalence of diabetic retinopathy was $22.3 \%$, the most common prevalence age was 51 - 70 years ( $81 \%$ of cases). Prevalence of cataract was $30.5 \%$. $23.4 \%$ of patients were with cardiovascular disease; $4.7 \%$ of patients were with chronic kidney disease; $3 \%$ of patients had cerebrovascular events; $13.7 \%$ of the patients were smokers; and 65.6 percent had a family history of diabetes.

Furthermore, $60 \%$ of patients were with albuminuria $\mathrm{BP} \geq 125.75$; and $55.3 \%$ of patients were without albuminuria $\mathrm{BP} \geq 130 / 80$.

Levels of fasting blood glucose, 24-hour urinary albuminuria, glycosylated hemoglobin (HbA1C), duration of diabetes and systolic blood pressure were differed among patients with and without retinopathy (Table 1).

The blood pressure $60 \%$ of patients with albuminuria group and $55.3 \%$ of patients in the group without albuminuria were higher than goals of blood pressure control.

Diabetic retinopathy associated with Duration of diabetes and BMI, OR $=0.98$ (95\% CI: $0.98-0.99)$ P value $=$ $0.0001, \mathrm{OR}=0.93(95 \%$ CI: $0.86-0.99)$ and P value $=0.043$ respectively (Table 2).

There were not significant difference between subject with \& without diabetic retinopathy in total cholesterol LDL, HDL, TG, Cr, Diastolic BP, types of treatment, cardiovascular disease, chronic kidney disease, stroke \& smoking.

Table 1. Comparison risk factors among patients with and without retinopathy.

\begin{tabular}{|c|c|c|c|c|c|c|}
\hline & Diabetic Retinopathy & Number & Mean & SD & P.V & $95 \%$ CI \\
\hline \multirow{2}{*}{ Chol } & Yes & 57 & 183.9 & 46.6 & \multirow{2}{*}{0.75} & \multirow{2}{*}{$-10.6-14.8$} \\
\hline & No & 199 & 181.8 & 42 & & \\
\hline \multirow{2}{*}{ LDL } & Yes & 57 & 104 & 41.4 & \multirow{2}{*}{0.19} & \multirow{2}{*}{$-3.98-19.86$} \\
\hline & No & 199 & 96.1 & 33.8 & & \\
\hline \multirow{2}{*}{ HDL } & Yes & 57 & 47.3 & 10.9 & \multirow{2}{*}{0.57} & \multirow{2}{*}{$-4.25-2.36$} \\
\hline & No & 199 & 48.2 & 11.26 & & \\
\hline \multirow{2}{*}{ TG } & Yes & 57 & 161.6 & 86.12 & \multirow{2}{*}{0.09} & \multirow{2}{*}{$-68.1-5.39$} \\
\hline & No & 199 & 193 & 133 & & \\
\hline \multirow{2}{*}{$\mathrm{Cr}$} & Yes & 57 & 0.98 & 0.3 & \multirow{2}{*}{0.31} & \multirow{2}{*}{$-0.03-0.11$} \\
\hline & No & 199 & 0.94 & 0.2 & & \\
\hline \multirow[b]{2}{*}{ FBS } & Yes & 57 & 191.1 & 83.33 & \multirow[b]{2}{*}{0.03} & \multirow[b]{2}{*}{$2.76-4804$} \\
\hline & No & 199 & 165.8 & 74.4 & & \\
\hline \multirow{2}{*}{24 Urine alb } & Yes & 57 & 181.3 & 404.7 & \multirow{2}{*}{0.03} & \multirow{2}{*}{$8.82-233.2$} \\
\hline & No & 199 & 60.3 & 238.9 & & \\
\hline \multirow{2}{*}{ BMI } & Yes & 57 & 28.95 & 4.94 & \multirow[b]{2}{*}{0.2} & \multirow[b]{2}{*}{$-0.49-2.29$} \\
\hline & No & 199 & 28.05 & 4.65 & & \\
\hline \multirow{2}{*}{ SBP } & Yes & 57 & 124.3 & 21.28 & \multirow{2}{*}{0.04} & \multirow{2}{*}{$0.29-11.21$} \\
\hline & No & 199 & 118.5 & 17.8 & & \\
\hline \multirow{2}{*}{ DBP } & Yes & 57 & 77.9 & 11.6 & \multirow{2}{*}{0.14} & \multirow{2}{*}{$0.81-5.8$} \\
\hline & No & 199 & 75.4 & 11 & & \\
\hline \multirow[b]{2}{*}{ Duration of DM } & Yes & 57 & 153 & 88.38 & \multirow[b]{2}{*}{0.0004} & \multirow[b]{2}{*}{$51.5-101.8$} \\
\hline & No & 199 & 76.32 & 66.68 & & \\
\hline the $1 C$ & Yes & 57 & 9.14 & 2.07 & בית & 5ר 1 \\
\hline 110R10 & No & 199 & 8.47 & 1.92 & 0.02 & $0.05-1.25$ \\
\hline
\end{tabular}

${ }^{*} \mathrm{P}<0.05$ significant. 
Table 2. Association of risk factors with diabetic retinopathy.

\begin{tabular}{cccc}
\hline Risk Factors & Odd Ratio & 95\% Confidence Interval & P.V \\
\hline Duration of D.M & 0.98 & $0.98-0.99$ & 0.0001 \\
BMI & 0.93 & $0.86-0.99$ & 0.043 \\
Insulin or Tablets & 0.74 & $0.43-1.28$ & 0.29 \\
Cardiovascular Disease & 0.63 & $0.25-1.56$ & 0.32 \\
Chronic Kidney Disease & 2.37 & $0.26-21.1$ & 0.43 \\
Smoking & 2.61 & $0.9-7.57$ & 0.07 \\
Stroke & 0.38 & $0.02-5.11$ & 0.46 \\
\hline
\end{tabular}

${ }^{*} \mathrm{P}<0.05$ significant.

\section{Discussion}

In current study, the prevalence of diabetic retinopathy in the patients with known diabetes was $22.3 \%$, which was more than a prevalence of retinopathy of $17.6 \%$ in India, based on Cures's study, and less than a prevalence of the $25.7 \%$ of retinopathy in the Chinese-Americans residents in America [8]. If we had an access to Stereoscopic fundus photography or the Stereoscopic digital retinal images, then, we could discover a higher percentage of diabetic retinopathy that is undetected by indirect Fundoscopy. 60\% of patients with albuminuria group and $55.3 \%$ of patients in the group without albuminuria lacked proper blood pressure based on the treatment goals [9].

In current study, long duration of diabetes and high BMI were established risk factors for diabetic retinopathy which was similar to a study done in Singapore among patients with diabetes mellitus [4].

Other risk factors for retinopathy were high levels of glycosylated hemoglobin, (HbA1C) and fasting blood glucose and systolic blood pressure and 24-hour urinary albuminuria. Similar results about of glycosylated hemoglobin and systolic blood pressure were shown in the study of Singapore [4] and America Los Angeles [10] respectively.

We could not find associations between diabetic retinopathy and total cholesterol, TG, HDL, LDL, insulin therapy (similar to Los Angeles Study) but Singapore study showed effects of total cholesterol in diabetic retinopathy. Our study could find any association between diabetic retinopathy creatinine. The study in Singapore showed a relationship between sight-threatening retinopathies with previous history of stroke, cardiovascular disease and chronic kidney disease. Additionally, a prospective multi-center study [11] suggests the relationship between smoking and diabetic retinopathy. In a study that was conducted in Tehran, and the relationship between diabetic retinopathy and nephropathy was shown, but our study showed that there was no significant relationship among diabetic retinopathy and coronary heart disease, chronic kidney disease, smoking, and history of stroke [12].

This evidence suggests that the risk of occurrence of diabetic retinopathy is associated with modifiable and non-modifiable factors that can be reduced by controlling its modifiable factors such as high blood sugar, high blood pressure and the risk reduction of microalbuminuria and weight loss in patients with diabetes.

\section{Acknowledgements}

This paper issued from Drs. Ferdos Zaman thesis register number D/130. Financial support was provided by Health Research Institute, Diabetes Research Center, Ahvaz Jundishapur University of Medical Sciences.

\section{Competing Interests}

The authors declare that they have no competing interests.

\section{References}

[1] Cugati, S., Kifley, A., Mitchell, P. and Wang, J.J. (2006) Temporal Trends in the Age-Specific Prevalence of Diabetes and Diabetic Retinopathy in Older Persons: Population-Based Survey Findings. Diabetes Research and Clinical Prac- 
tice, 74, 301-308. http://dx.doi.org/10.1016/j.diabres.2006.04.002

[2] Candrilli, S.D., Davis, K.L., Kan, H.J., Lucero, M.A. and Rousculp, M.D. (2007) Prevalence and the Associated Burden of Illness of Symptoms of Diabetic Peripheral Neuropathy and Diabetic Retinopathy. Journal of Diabetes and its Complications, 21, 306-314. http://dx.doi.org/10.1016/j.jdiacomp.2006.08.002

[3] Wang, F.H., Liang, Y.B., Zhang, F., Wang, J.J., Wei, W.B. and Tao, Q.S. (2009) Prevalence of Diabetic Retinopathy in Rural China: The Handan Eye Study. Ophthalmology, 116, 461-467. http://dx.doi.org/10.1016/j.ophtha.2008.10.003

[4] Wong, T.Y., Cheung, N., Tay, W.T., Wang, J.J., Aung, T. and Saw, S.M. (2008) Prevalence and Risk Factors for Diabetic Retinopathy: The Singapore Malay Eye Study. Ophthalmology, 115, 1869-1875. http://dx.doi.org/10.1016/j.ophtha.2008.05.014

[5] Olafsdottir, E., Andersson, D.K., Dedorsson, I. and Stefánsson, E. (2014) The Prevalence of Retinopathy in Subjects with and without Type 2 Diabetes Mellitus. Acta Ophthalmologica, 92, 133-137. http://dx.doi.org/10.1111/aos.12095

[6] Targher, G., Bertolini, L., Zenari, L., Lippi, G., Pichiri, I. and Zoppini, G. (2008) Diabetic Retinopathy Is Associated with an Increased Incidence of Cardiovascular Events in Type 2 Diabetic Patients. Diabetic Medicine, 25, 45-50. http://dx.doi.org/10.1111/j.1464-5491.2007.02327.x

[7] Ramavat, P.R., Ramavat, M.R., Ghugare, B.W., Vaishnav, R.G. and Joshi, M.U. (2013) Prevalence of Diabetic Retinopathy in Western Indian Type 2 Diabetic Population: A Hospital-Based Cross-Sectional Study. Journal of Clinical and Diagnostic Research, 7, 1387-1390.

[8] Rema, M., Premkumar, S., Anitha, B., Deepa, R., Pradeepa, R. and Mohan, V. (2005) Prevalence of Diabetic Retinopathy in Urban India: The Chennai Urban Rural Epidemiology Study (CURES) Eye Study, I. Investigative Ophthalmology \& Visual Science, 46, 2328-2333. http://dx.doi.org/10.1167/iovs.05-0019

[9] Mohamed, Q., Gillies, M.C. and Wong, T.Y. (2007) Management of Diabetic Retinopathy: A Systematic Review. JAMA, 298, 902-916. http://dx.doi.org/10.1001/jama.298.8.902

[10] Keech, A.C., Mitchell, P., Summanen, P.A., O’Day, J., Davis, T.M. and Moffitt, M.S. (2007) Effect of Fenofibrate on the Need for Laser Treatment for Diabetic Retinopathy (FIELD Study): A Randomised Controlled Trial. The Lancet, 370, 1687-1697. http://dx.doi.org/10.1016/S0140-6736(07)61607-9

[11] He, B.B., Wei, L., Gu, Y.J., Han, J.F., Li, M. and Liu, Y.X. (2012) Factors Associated with Diabetic Retinopathy in Chinese Patients with Type 2 Diabetes Mellitus. International Journal of Endocrinology, 2012, Article ID: 157940. http://dx.doi.org/10.1155/2012/157940

[12] Rafati, N., Dehghan, M.H., Javadi, M.A., Souri, H., Zaeri, F. and Gooya, M.M. (2008) The Prevalence of Diabetic Retinopathy in Tehran Province. BMC Ophthalmology, 13, 166-175. 
Scientific Research Publishing (SCIRP) is one of the largest Open Access journal publishers. It is currently publishing more than 200 open access, online, peer-reviewed journals covering a wide range of academic disciplines. SCIRP serves the worldwide academic communities and contributes to the progress and application of science with its publication.

Other selected journals from SCIRP are listed as below. Submit your manuscript to us via either submit@scirp.org or Online Submission Portal.
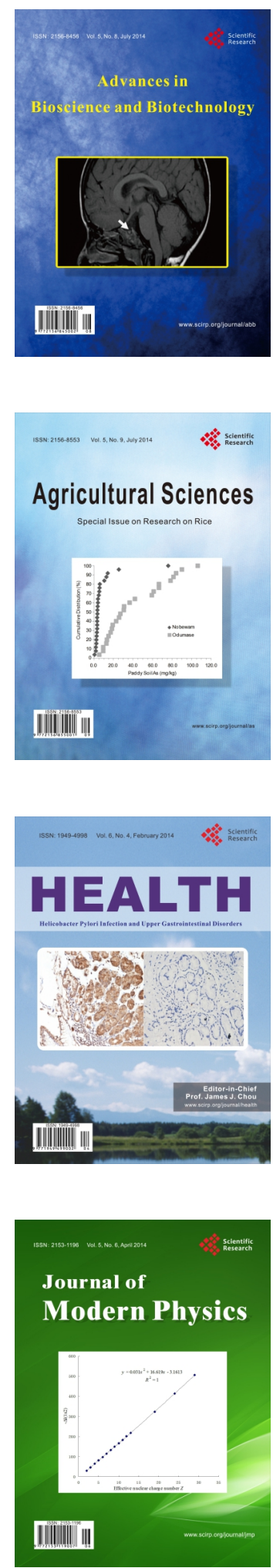
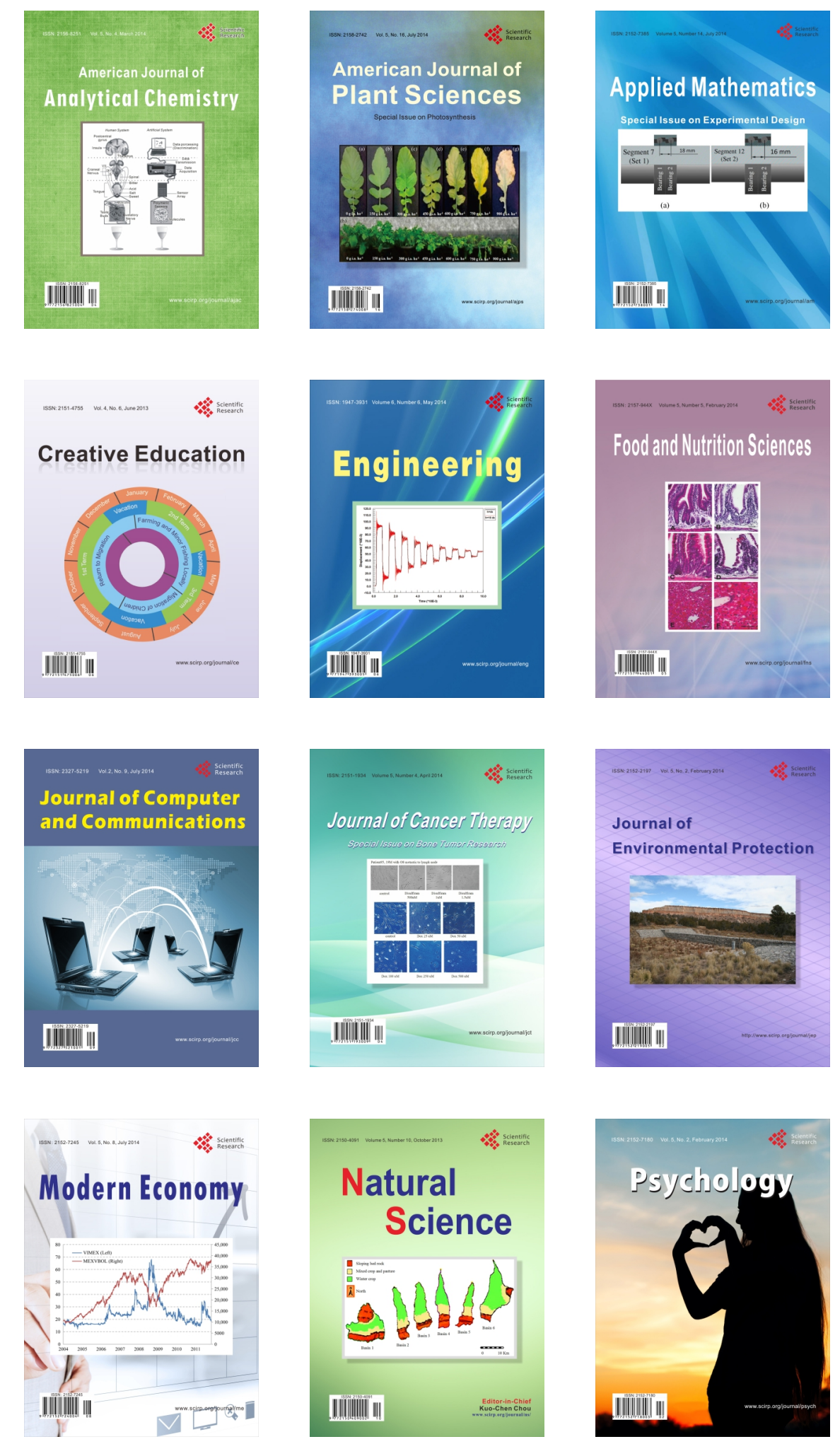